\title{
Global differences in the prevalence of the CpG island methylator phenotype of colorectal cancer
}

\author{
Shailesh Mahesh Advani ${ }^{1,2,3^{*}}$ D, Pragati Shailesh Advani ${ }^{4}$, Derek W. Brown ${ }^{5}$, Stacia M. DeSantis ${ }^{5}$, \\ Krittiya Korphaisarn ${ }^{1}$, Helena M. VonVille ${ }^{6}$, Jan Bressler ${ }^{7}$, David S. Lopez ${ }^{8,9}$, Jennifer S. Davis ${ }^{10}$, Carrie R. Daniel $^{10}$, \\ Amir Mehrvarz Sarshekeh ${ }^{1}$, Dejana Braithwaite ${ }^{2}$, Michael D. Swartz ${ }^{5}$ and Scott Kopetz ${ }^{1 *}$
}

\begin{abstract}
Background: CpG Island Methylator Phenotype (CIMP) is an epigenetic phenotype in CRC characterized by hypermethylation of $\mathrm{CpG}$ islands in promoter regions of tumor suppressor genes, leading to their transcriptional silencing and loss of function. While the prevalence of CRC differs across geographical regions, no studies have compared prevalence of CIMP-High phenotype across regions. The purpose of this project was to compare the prevalence of CIMP across geographical regions after adjusting for variations in methodologies to measure CIMP in a meta-analysis.

Methods: We searched PubMed, Medline, and Embase for articles focusing on CIMP published from 2000 to 2018. Two reviewers independently identified 111 articles to be included in final meta-analysis. We classified methods used to quantify CIMP into 4 categories: a) Classical (MINT marker) Panel group b) Weisenberg-Ogino (W-O) group c) Human Methylation Arrays group and d) Miscellaneous group. We compared the prevalence of CIMP across geographical regions after correcting for methodological variations using meta-regression techniques.

Results: The pooled prevalence of CIMP-High across all studies was 22\% (95\% confidence interval:21-24\%; $1^{2}=94.75 \%$ ). Pooled prevalence of CIMP-H across Asia, Australia, Europe, North America and South America was 22, 21, 21, 27 and $25 \%$, respectively. Meta-regression analysis identified no significant differences in the prevalence of CIMP-H across geographical regions after correction for methodological variations. In exploratory analysis, we observed variations in CIMP-H prevalence across countries.

Conclusion: Although no differences were found for CIMP-H prevalence across countries, further studies are needed to compare the influence of demographic, lifestyle and environmental factors in relation to the prevalence of CIMP across geographical regions.
\end{abstract}

Keywords: Epigenetics, Methylation, Geographic, CIMP, Colorectal

\section{Background}

Colorectal cancer $(\mathrm{CRC})$ poses a significant public health burden globally. In 2018, globally, CRC will account for approximately $6.1 \%$ of all new cancer cases $(n=1,096$, $601)$ and $5.8 \%$ of cancer related deaths $(n=551,269)$ globally [1]. Disparities in the incidence of CRC occur

\footnotetext{
* Correspondence: Shailesh.advani@nih.gov; skopetz@mdanderson.org 'Department of Gastrointestinal Medical Oncology, The University of Texas MD Anderson Cancer Center, 1515 Holcombe Blvd, Unit 0426, Houston, TX 77030, USA

Full list of author information is available at the end of the article
}

across geographical regions, with the highest incidence reported in Australia and lowest incidence in Africa [2]. Additionally, mortality rates associated with CRC vary across the globe, with high rates of mortality associated with CRC across Europe as compared to low mortality rates in Africa [2]. Furthermore, differences in CRC incidence exists within regions across age groups, gender, and racial/ethnic groups due to multiple factors, including lifestyle, screening behaviors, and biological factors [3]. Hence, understanding the prevalence and distribution of

(C) The Author(s). 2019 Open Access This article is distributed under the terms of the Creative Commons Attribution 4.0 International License (http://creativecommons.org/licenses/by/4.0/), which permits unrestricted use, distribution, and 
CRC could help guide tailored prevention, screening and treatment strategies.

The biological processes underlying the development of CRC are complex, with multiple genetic and epigenetic alterations dictating the transition from a normal colon epithelium to cancer. In recent years, much attention has been paid to the role of epigenetic alterations-changes in phenotype or gene expression that do not involve DNA sequence changes-in the development of CRC $[4,5]$. One type of epigenetic alteration associated with cancer is methylation of $\mathrm{CpG}$ islands in promoter regions of tumor suppressor genes which form hotspots for methylation changes. The $\mathrm{CpG}$ island methylator phenotype was first described in CRC by Toyota et al. who identified cancer specific methylation of tumor markers in CRC tissues and is now considered to be an initiating event of the serrated adenoma pathway in the development of CRC $[6,7]$. CIMP -High (CIMP-H) is now considered a distinct molecular subtype of sporadic colorectal cancer. It is characterized by a high degree of methylation in promoterassociated CpG-rich regions of tumor suppressor genes, which causes transcriptional inactivation of these genes and leads to cancer development and progression $[4,8]$.

Large-scale geographic comparisons of CIMP prevalence are limited because there is no consensus on the definition of CIMP and a wide array of methods used for measuring it [8]. In a recent systematic review, Hughes et al. concluded that no gold standard exists for determining CIMP and that no methodology has been shown to be superior to another [9]. Additionally, Jia et al. showed that the estimated prevalence of CIMP-H in CRC tumors ranged from 7 to $48 \%$, and described 16 different of varied genetic markers used to measure CIMP that were based on different threshold values of methylation at individual markers in panels or based on different cut-offs used for defining CIMP-H [10]. The first panel used to measure CIMP, termed the classical panel measures CIMP using the methylated in tumor (MINT) markers MINT1, MINT2, MINT31, CDKN2A, and MLH1 and defines $\mathrm{CIMP}-\mathrm{H}$ tumors as those expressing 2 or more of these methylated markers $[4,6]$. Subsequently, Weisenberger et al. [11] measured CIMP using a 5-marker panel consisting of CACNA1G, IGF2, NEUROG1, RUNX3, and SOCS1, and Ogino et al. [12] extended the Weisenberger panel, adding CDKN2A, CRABP1, and MLH1. These two panels have been widely used to measure CIMP. More recently, genome-wide methylation arrays have been used to study methylation changes across the human genome [13]. Technologies for quantifying CIMP have rapidly developed and include methylation-specific polymerase chain reaction (PCR), real-time PCR (such as MethyLight), and bisulfite pyrosequencing [9]. These technologies measure methylation differently: some at a single gene site, others across several CpG sites of a gene, and others across several genes $[9,14]$. Previous reviews have identified significant heterogeneity in pooled estimates of the clinical, pathological, and molecular characteristics of CIMP tumors, particularly due to differences in the methods used to assess CIMP across studies, selection criteria for CRC patient populations, laboratory methods, or geographic region of study $[4,8,15]$. Hence, it is important to consider utilization of CIMP methodologies across geographic areas while studying the geographical variation of estimates of CIMP prevalence.

Lifestyle factors are also shown to be associated with epigenetic changes and might influence prevalence of CIMP phenotype and CRC across geographical regions. Identifying potential differences in CIMP prevalence can help us explore potential factors underlying these differences and explain disparities in the incidence of CRC across geographical regions. It is, therefore, important to understand how CIMP prevalence varies geographically. The aim of this systematic review and meta-analysis was to assess the prevalence of CIMP across geographical regions after correcting for methodological variations using meta-regression techniques.

\section{Methods}

We utilized data from a comprehensive systematic review of clinical, pathological and molecular characteristics of CIMP tumors in CRC [15]. The original systematic review was registered with PROSPERO (registration number CRD42016034181). Included studies had to describe patients who were diagnosed with sporadic CRC and evaluated CIMP phenotype among these patients. We excluded studies that focused on hereditary CRC syndromes and studies focusing on premalignant lesions such as adenomas or polyps within CRC. Additionally, studies focused on other cancers or that did not have a clear description of the measurement or quantification of CIMP were excluded. Original research published in the journal literature was required; review articles were excluded as were conference proceedings. Lastly, we limited articles to those published in English, in peer-reviewed journals.

\section{Search strategy}

The Medline (Ovid), PubMed (National Library of Medicine), and Embase (Ovid) databases were searched with the assistance of a health sciences librarian (HV). The initial searches were completed in April 2016; two updated PubMed searches were completed, one on January 3, 2017 and the other on April 25, 2018. The three main concepts that made up our search were: CIMP or CpG island methylator phenotype/methylation, sporadic CRC, and clinical/ pathological and molecular characteristics. A combination of medical subject heading $(\mathrm{MeSH})$ terms and terms included in the title, abstract, and keywords were used to develop the initial Medline search. This search was then 
adapted for the other databases. Additional file 1 provides an overview of the search strategies used for each database. RefWorks (ProQuest) was used to store all citations found in the search process and to check for duplicates.

\section{Study selection}

An online random number generator (https://www. random.org/integers/) was used to create a random sample of 66 numbers that were then input into an Excel workbook designed specifically for the Cohen's kappa interrater reliability test [16]. If there were any duplicate numbers, one was replaced by choosing a number between the pair and the number below or above. The numbers corresponded to line numbers within the Excel workbook which resulted in a random sample of titles and abstracts; authors and journal titles were not included in the sample. Two authors (SA, PA) independently screened the sample and reached good interrater agreement (Cohen's $\mathrm{K}=0.77$ ). After resolving discrepancies in the interrater reliability test through mutual discussion, the same authors then independently screened all titles and abstracts, still blinded to authors and journal titles, using an Excel workbook designed specifically for this step of the systematic review process [16]. Data were compiled into a single Excel workbook at which time consensus was reached on items in which there was disagreement. Articles considered for inclusion were independently reviewed by two authors (SA, PA) and consensus reached by discussion on any disagreements for inclusion. The Excel workbooks also served as our primary tool for gathering all search strategy data and for the creation of the Preferred Reporting Items for Systematic Reviews and Meta-Analyses (PRISMA) flowchart [17].

\section{Data abstraction}

The primary author (SA) identified key study characteristics, including study design, first author, cohort description, and country, and extracted information on the panel markers and/or methodology used to determine CIMP, the cutoff for classifying various CIMP groups in each study, and the prevalence of each CIMP subgroup.

\section{CIMP classification}

Studies generally classified CIMP into three groups: CIMP-High, CIMP-Low and CIMP-0. A few studies also classify CIMP as CIMP+ and CIMP-. For analytical purposes, we coded the classifications of CIMP-H and CIMP+ as CIMP-H and analogously, we coded CIMPLow, CIMP-, and CIMP-0 as CIMP-0.

\section{Methodological classification}

We classified CIMP methodologies into four groups: (i) the classical panel or MINT marker group, (ii) WiesenbergerOgino (W-O) marker panels, and (iii) human methylation array panels and (iv) Miscellaneous. The human methylation arrays included the Infinium HumanMethylation27 BeadChip and Infinium HumanMethylation450 BeadChip (Illumina, Inc., San Diego, CA) [18, 19]. Methodologies that did not fit into any of these 3 categories were categorized as "miscellaneous."

\section{Meta-analysis}

We calculated the pooled prevalence of CIMP-H across studies using a random effects model [20]. A measure of study heterogeneity $\left(\mathrm{I}^{2}\right)$ was calculated; $\left(\mathrm{I}^{2}\right)$ of $>50 \%$ is considered to indicate statistical heterogeneity. Using this method, we calculated pooled prevalence estimates of the CIMP-H subcategory for Asia, Australia, Europe, North America, and South America. No pooled estimate could be calculated across Africa because only one study was identified from the African continent. Additionally, we calculated the pooled prevalence of CIMP-H phenotype across methods described above. Furthermore, country specific prevalence of the CIMP-H group was estimated using a random effects model.

\section{Meta-regression}

We performed a meta-regression analysis to compare CIMP-H prevalence across methodological groups and geographical regions using a random effects model [21]. In the first step, using unadjusted meta-regression analysis, we compared the mean prevalence of CIMP-H across continents, using North America as the reference group. To assess whether differences in methodology accounted for differences in CIMP-H prevalence across continents, we reran meta-regression analysis across geographical regions adjusting for methodological subtype.

\section{Bias and quality assessment}

We performed quality assessment on the included studies. For cohort and case-control studies, the NewcastleOttawa Scale was utilized [22]. This scale assesses quality of included studies on three groups: Selection, Comparability, and Assessment. For cohort studies, these include selection strategy of cohort, comparability of exposed and non-exposed cohort, and assessment of outcome and follow-up data. For case control, these include selection strategy of cases and controls, comparability of cases and controls, and ascertainment of exposure, including ascertainment of cases and controls and response rates. Reviewers rate studies on scale of $0-4$ for selection, scale of 0-2 for comparability, and scale of $0-3$ for ascertainment respectively. Egger's test was utilized to assess for publication bias due to sample size [23]. Finally funnel plots were plotted to assess for publication bias [24]. 


\section{Results}

\section{Screening process}

Our search identified 4377 records. After removal of duplicates, two screeners (SA, PA) screened 2313 abstracts and identified 749 articles for full text review. Figure 1 provides a PRISMA flowchart of the screening process. Of total 749 screened, 279 articles were excluded because they did not report original research, 43 articles did not include a clear description of CIMP, and 90 articles were excluded for other reasons, including a focus on premalignant lesions such as adenomas or polyps or inadequate information on CIMP measurements or methodologies. The final sample consisted of 337 publications for overall analysis.

\section{Patient population}

The 337 included articles represented a total of 111 cohorts and 26 countries. To avoid bias from repeated inclusion of the same patients, we restricted our analysis to 111 cohorts, using data from each cohort with largest sample size. Our final analysis was based on 111 studies that included 37,585 CRC patients (Fig. 1).

\section{Meta-analysis of CIMP prevalence}

We calculated a pooled prevalence of CIMP-H across the included 111 studies [14, 25-133]. The pooled prevalence of CIMP-H was $22 \%$ (95\% confidence interval [CI], 21$24 \% ; I^{2}=95.68 \%$ ). Additionally, 30 studies reported prevalence of CIMP-low (CIMP-L) and CIMP-0. The pooled

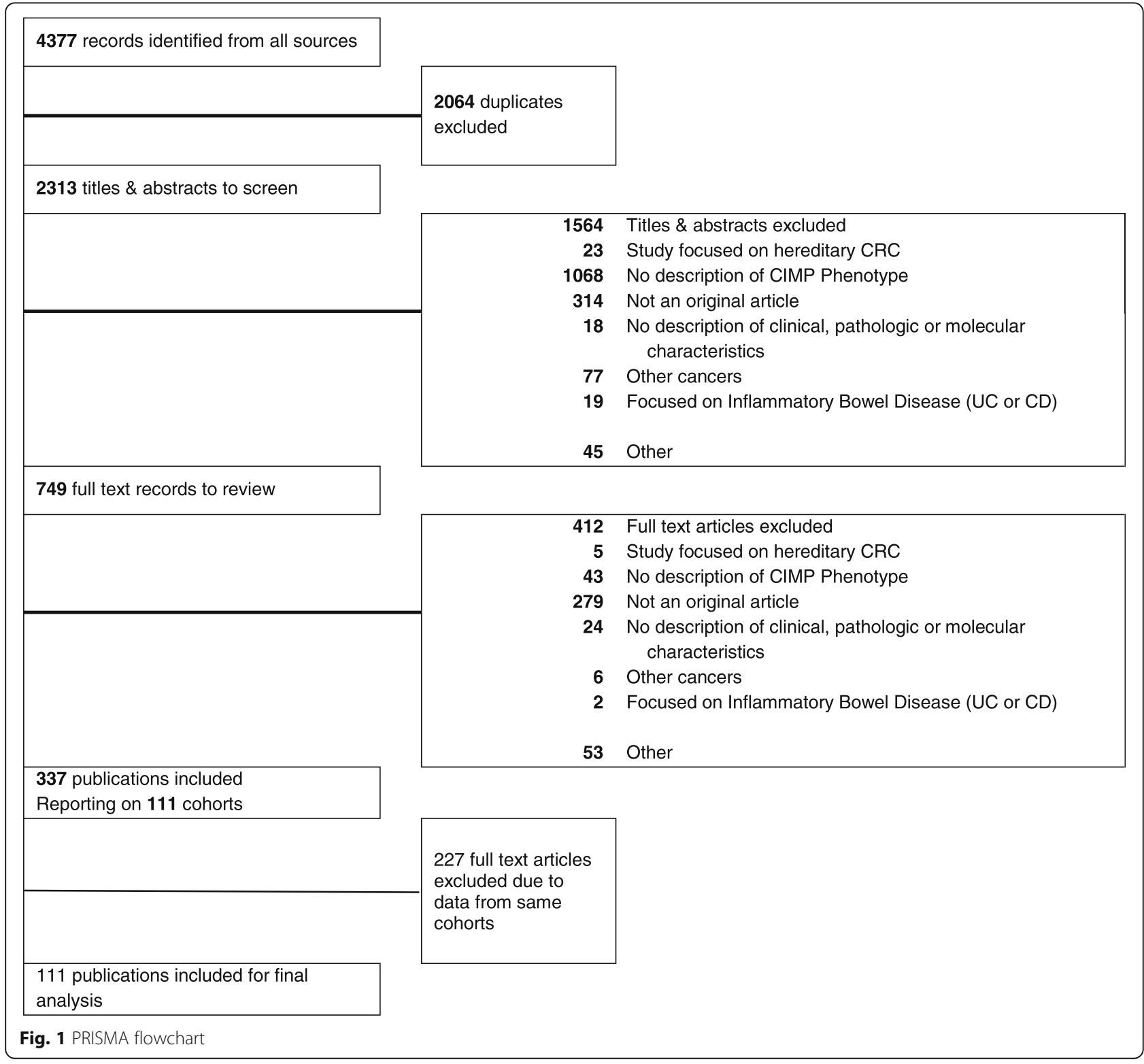


prevalence of CIMP-L was 34\% (95\% CI, 30-39\%; $\mathrm{I}^{2}=$ $94.73 \%)$, and the pooled prevalence of CIMP-0 was $47 \%$ (95\% CI, 40-53\%; I $\left.{ }^{2}=96.65 \%\right)$ [25, 27, 30, 35, 41, 44-46, $49,50,52,54,57,59,60,62,64,76,77,83,105,111,117-$ $119,121,123,126,131,133]$.

\section{Summary of CIMP methodologies}

The included studies provided information on over 60 different methods or combinations of markers/panels to determine or measure CIMP (Additional file 2: Table S2). We classified these methodologies into 4 groups: MINT marker panel (classical panel), W-O panels, and the human methylation arrays (27 k or $450 \mathrm{k}$ panel). Methods that did not fit into either three were grouped as "miscellaneous". Additional file 2: Table S2 provides a table with detailed information on the methods used in the studies, including the cutoffs used to define CIMP subgroups and the countries these methods were used in.

\section{Measuring CIMP-H prevalence across continents}

We calculated pooled prevalence estimates of CIMP-H for Asia, Europe, Australia, North America and South America using random effects model. The pooled CIMP-H prevalence across Asia, Australia, Europe, North America and South America were 22\% (95\% CI, 18-26\%; $\mathrm{I}^{2}=$ 95.74\%); $21 \%$ (95\% CI, 14-28\%; I $\left.{ }^{2}=97.77 \%\right) ; 21 \%$ (95\% CI, $18-24 \% ; I^{2}=94.78 \%$ ); $27 \%$ (95\% CI, 23-31\%; $\mathrm{I}^{2}=96.76 \%$ ) and $25 \%$ (95\% CI, 18-31\%; $\mathrm{I}^{2}=$ not available), respectively. Only 1 study was available from the African subcontinent, from Tunisia. Nine studies included more than 1 country and were not included in the analysis of prevalence across continents $[25,42,44,45,63,69,88,108,115]$. Figure 2 provides an overview of pooled prevalence across countries.

\section{CIMP prevalence by methodology}

We measured the pooled prevalence of CIMP-H for each of the 3 methods used to determine CIMP: MINT marker panel, W-O panel, and human methylation arrays. The pooled prevalence of CIMP-H across these groups were $26 \%$ (95\% CI, 23-29\%; I ${ }^{2}=93.89 \%$ ); $21 \%$ (95\% CI: $\left.18-23 \% ; \mathrm{I}^{2}=96.70 \%\right)$ and $22 \%$ (95\% CI: $13-$ $31 \% ; \mathrm{I}^{2}=91.06 \%$ ), respectively.

\section{Meta-regression analysis}

Both unadjusted and adjusted meta-regression analysis identified no significant differences in CIMP-H prevalence across geographical regions (Table 1).

\section{Prevalence by country}

Based on available data, we calculated CIMP-H prevalence across countries, and found that CIMP-H prevalence varied widely across countries globally, and within continents (Table 2). CIMP-H prevalence ranged from a low of $6 \%$ in Saudi Arabia to high of $50 \%$ in Czech Republic. Figure 3 provided a global representation of variation in CIMP-H prevalence across countries.

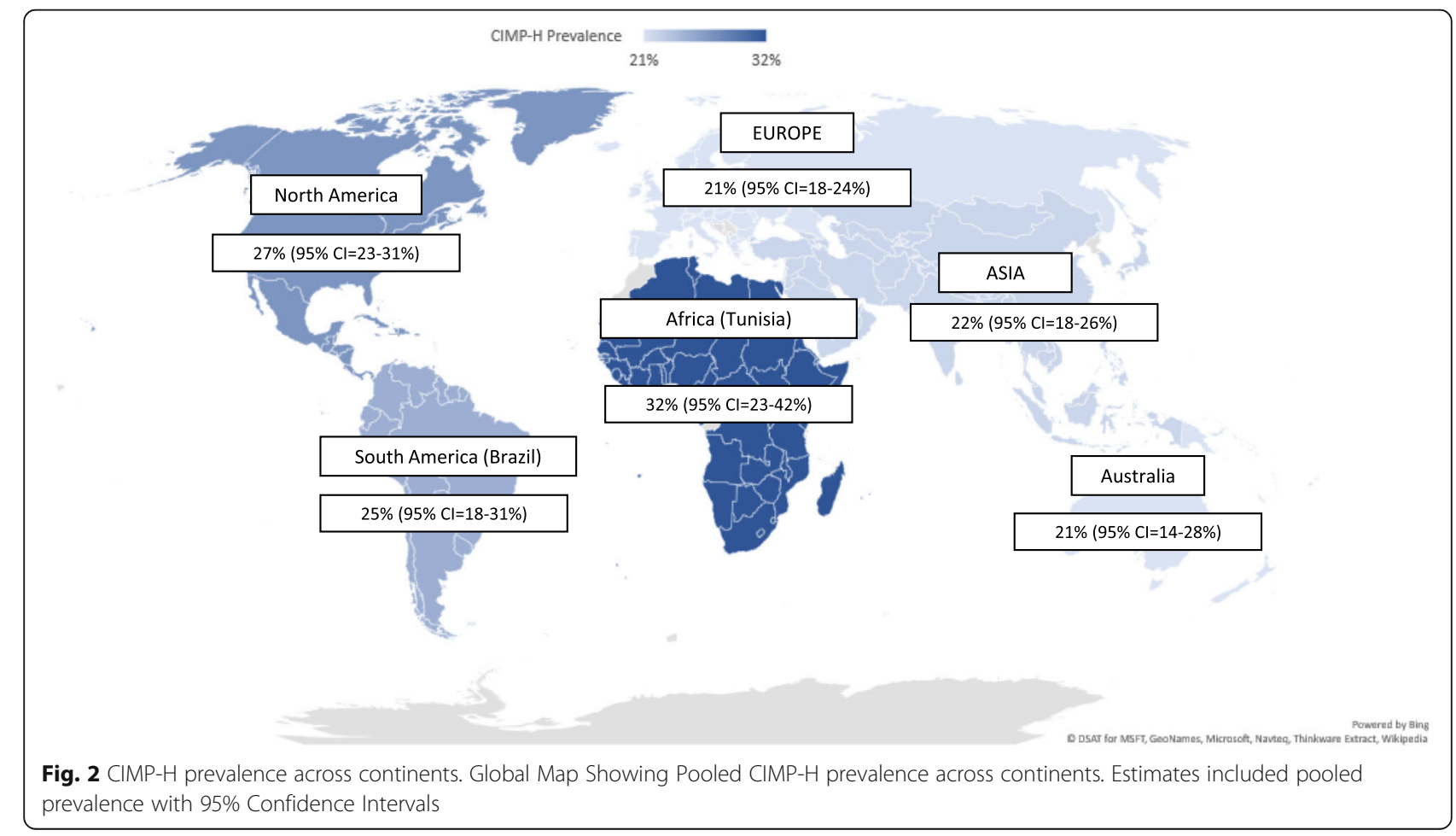


Table 1 Metaregression analysis of comparison of CIMP-H prevalence across continents. Using North America as the reference group, pooled prevalence using unadjusted and adjusted estimates are shown

\begin{tabular}{llllllll}
\hline & N Studies & $\mathrm{N}$ (Total sample size) & $\mathrm{N}$ (Total CIMP-H) & $\begin{array}{l}\text { Mean CIMP-H } \\
\text { prevalence }\end{array}$ & $\begin{array}{l}\text { 95\% confidence } \\
\text { interval }\end{array}$ & $\begin{array}{l}\text { P-Value for unadjusted } \\
\text { metaregression }\end{array}$ & $\begin{array}{l}P \text {-Value for adjusted } \\
\text { metaregression }\end{array}$ \\
\hline North America & 19 & 13,138 & 2162 & $27 \%$ & $23-31 \%$ & Ref & Ref \\
Asia & 30 & 6628 & 1113 & $22 \%$ & $18-26 \%$ & 0.24 & 0.35 \\
Australia & 12 & 4315 & 618 & $21 \%$ & $14-28 \%$ & 0.19 & 0.35 \\
Europe & 37 & 7926 & 1583 & $21 \%$ & $18-24 \%$ & 0.15 & 0.31 \\
South America & 2 & 159 & 40 & $25 \%$ & $18-31 \%$ & 0.66 & 0.90 \\
\hline
\end{tabular}

\section{Correlation of CIMP-H phenotype with prevalence of lifestyle factors across countries}

Using statistics from the World Health Organization [134], we measured the prevalence of risk factors previously associated with CRC [135-137]: obesity $\left(\mathrm{BMI}>=30 \mathrm{~kg} / \mathrm{m}^{2}\right)$, alcohol intake (ever drinkers) and smoking (ever-smoker) with measured CIMP-H prevalence across countries (Table 2). CIMP-H was significantly corelated with alcohol intake (Pearson correlation $=0.51, p=0.01)$. No significant correlation was observed with the prevalence of obesity (Pearson correlation $=-0.24, p=0.23$ ) or smoking (Pearson correlation $=-0.004, p=0.98)$. Though these correlations do not imply causation, it provides evidence of possible association of alcohol intake associated epigenetic changes with CIMP phenotype in CRC and warrants further exploration in future studies.

Table 2 Meta- Analysis for CIMP-H prevalence across countries

\begin{tabular}{|c|c|c|c|c|c|c|}
\hline Continent & Country & Mean CIMP-H prevalence & $95 \% \mathrm{Cl}$ & Smoking \% & Alcohol drinkers \% & Obesity\% \\
\hline Africa & Tunisia & $32 \%$ & $23-42 \%$ & $40.93 \%$ & $20 \%$ & $27 \%$ \\
\hline \multirow[t]{2}{*}{ Australia } & Australia & $20 \%$ & $13-27 \%$ & $14.8 \%$ & $11.9 \%$ & $29 \%$ \\
\hline & New Zealand & $35 \%$ & $26-45 \%$ & $14.9 \%$ & $12 \%$ & $31 \%$ \\
\hline \multirow[t]{7}{*}{ Asia } & China & $24 \%$ & $12-35 \%$ & $25.2 \%$ & $10.6 \%$ & $6 \%$ \\
\hline & India & $44 \%$ & $37-51 \%$ & $11.3 \%$ & $22.3 \%$ & $4 \%$ \\
\hline & Japan & $26 \%$ & $20-32 \%$ & $22.5 \%$ & $9.90 \%$ & $4 \%$ \\
\hline & Taiwan & $16 \%$ & $12-20 \%$ & $18 \%$ & NA & NA \\
\hline & South Korea & $21 \%$ & $11-31 \%$ & 23.6 & $19.90 \%$ & $7 \%$ \\
\hline & Kuwait & $9 \%$ & $5-16 \%$ & $19.9 \%$ & $3.10 \%$ & $38 \%$ \\
\hline & Saudi Arabia & $6 \%$ & $3-10 \%$ & $13.6 \%$ & NA & $35 \%$ \\
\hline \multirow[t]{14}{*}{ Europe } & Greece & $10 \%$ & $6-15 \%$ & $43.7 \%$ & $15 \%$ & $25 \%$ \\
\hline & Italy & $21 \%$ & $14-28 \%$ & $23.8 \%$ & $13 \%$ & $20 \%$ \\
\hline & Spain & $24 \%$ & $18-31 \%$ & $29.4 \%$ & $21 \%$ & $24 \%$ \\
\hline & France & $17 \%$ & $15-19 \%$ & $32.9 \%$ & $14.90 \%$ & $22 \%$ \\
\hline & Switzerland & $9 \%$ & $6-12 \%$ & $25.8 \%$ & $13.40 \%$ & $20 \%$ \\
\hline & United Kingdom & $12 \%$ & $1-24 \%$ & $22.4 \%$ & $15.60 \%$ & $28 \%$ \\
\hline & Netherlands & $34 \%$ & $21-48 \%$ & $25.9 \%$ & $13.90 \%$ & $20 \%$ \\
\hline & Norway & $19 \%$ & $17-21 \%$ & $20.2 \%$ & $8.70 \%$ & $23 \%$ \\
\hline & Sweden & $13 \%$ & $11-15 \%$ & $18.9 \%$ & $12.50 \%$ & $21 \%$ \\
\hline & Denmark & $38 \%$ & $35-42 \%$ & $19.1 \%$ & $14.40 \%$ & $20 \%$ \\
\hline & Germany & $16 \%$ & $12-20 \%$ & $30.7 \%$ & $13.40 \%$ & $22 \%$ \\
\hline & Poland & $25 \%$ & $19-31 \%$ & $28.2 \%$ & $17.90 \%$ & $23 \%$ \\
\hline & Czech Republic & $50 \%$ & $42-59 \%$ & $34.4 \%$ & $19.50 \%$ & $26 \%$ \\
\hline & Ireland & $43 \%$ & $29-58 \%$ & $24.4 \%$ & $19.30 \%$ & $25 \%$ \\
\hline North America & United States & $27 \%$ & $23-31 \%$ & $21.9 \%$ & $14.40 \%$ & $36 \%$ \\
\hline South America & Brazil & $25 \%$ & $18-31 \%$ & $14 \%$ & $18.50 \%$ & $22 \%$ \\
\hline
\end{tabular}




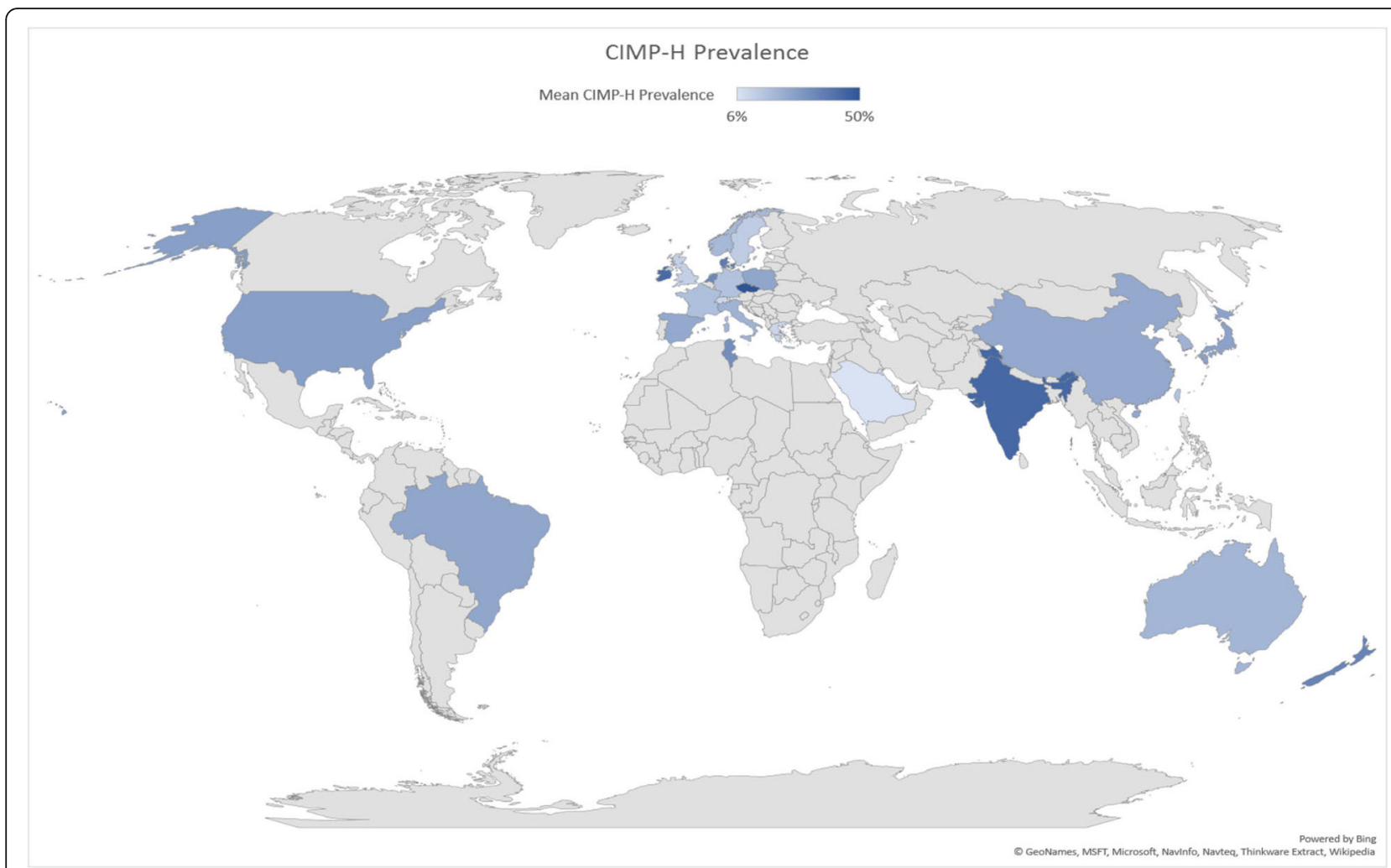

Fig. $3 \mathrm{CIMP}-\mathrm{H}$ prevalence across countries

\section{Bias and quality assessment}

Our results identified significant heterogeneity as assessed by funnel plots for pooled prevalence across studies. Additional file 3: Figure S1 depicts funnel plots for assessing publication bias for pooled CIMP-H prevalence. Additionally, possible heterogeneity was also observed in funnel plots for CIMP-H prevalence measures across panel types and continents (Additional file 3). We found evidence for publication bias, as seen by significant Egger's Publication Bias test $(p=0.014)$ in pooled CIMP-H prevalence, as well as in pooled prevalence across North America $(p=0.03)$. Quality assessment results for cohort and case control studies using the NewCastle Ottawa scale has been summarized in Additional files 4 and 5 respectively.

\section{Discussion}

To our knowledge, this is the first systematic review to assess differences in the prevalence of CIMP phenotype in CRC across geographical regions. We found pooled prevalence of CIMP-H to be $22 \%$ across all studies. Additionally, the pooled prevalence of CIMP-H varied from 21 to $27 \%$ across geographical regions, and metaregression analysis did not identify any significant differences in pooled prevalence across geographical regions, after adjusting for methodological differences. Moreover, our literature search identified over 60 combinations of panels and methods to measure CIMP, highlighting the rapidly evolving methodologies and technologies used to measure CIMP, differences in its utility across geographical regions, and the need to develop consensus on identifying a gold standard for measuring CIMP across geographical regions.

The incidence of CRC varies across different regions of the world [138, 139]. For example, the overall incidence of CRC in Australia is among the highest in the world, approximately $40 \%$ higher than in the United States (12\% vs $8.6 \%$ ) [139]. Previous studies have also found a higher incidence of CRC and a higher ratio of colon to rectal cancers in Western than in Asian populations [138-141]. The reasons for these differences are likely complex and involve differences in risk factors associated with CRC including lifestyle, genetic and epigenetic factors as well as screening practices across geographical regions [142]. Though our analysis did not find significant differences in CIMP prevalence across geographical regions, variation in other molecular subsets across geographical regions is warranted. CRC has been shown to be associated with lifestyle factors such as a diet high in red or processed meat, inadequate consumption of fruits and vegetables, smoking, obesity, and lack of physical activity [143]. Lifestyle factors have been 
postulated to induce inflammation through various mechanisms including epigenetic changes like hypermethylation [144]. Alcohol consumption may influence carcinogenesis through several possible mechanisms, including altering DNA methylation patterns by affecting intestinal absorption, hepatobiliary metabolism, and renal excretion of folate [145]. One study in Germany found higher consumption of alcohol among patients diagnosed with CIMP-L (but not CIMP-H) CRC tumors [110]. Another study found that the type of alcohol consumed (wine or beer) can affect the development of CIMP tumors [146]. Smoking too has been shown to be associated more with proximal than distal CRCs, suggesting differential changes induced by tobacco exposure on CRC pathways [147]. As CIMP is more common in proximal than in distal CRCs, smoking may be involved in the development of CIMP-high cancers associated with proximal tumor location [11]. Samowitz et al. reported higher odds of CIMP-H CRC tumors among smokers versus nonsmokers $(\mathrm{OR}=2.06,95 \% \mathrm{CI}=1.43$ to 2.97) [148]. In a study comparing the development of CIMP tumors by smoking status, a shorter time since cessation of smoking was associated with a higher risk of developing CIMP-H CRC [149]. Slattery et al. observed an association between a high body mass index (BMI) and CIMP- Low but not CIMP-High colon tumors and no association between BMI and CIMP status in rectal tumors [150]. In addition, one study reported that overweight or obesity was associated with the development of CIMP-H tumors [29].

Dietary factors also play a key role in CRC development. Certain dietary components have shown to be associated with inducing systemic and gastrointestinal specific inflammation, leading to increase in levels of pro-inflammatory cytokines including IL-1, IL-6 and TNF-a, and activation of downstream oncogenic signaling pathways [151]. Differences in total and red meat intake have been observed between the United States and other developed countries [152]. Diets low in methylcontributing folate, vitamins B6 and B12, methionine and high consumption of alcohol, affect DNA methylation and have been shown to result in increased risk of cancers with CpG island methylation [145]. Lastly, the combination of high inflammatory diets comprising of saturated fatty acids, high levels of sugar, red and processed meat, coupled with low dietary fibers and green leafy vegetables promote inflammation through increase in levels of pro-inflammatory cytokines [151]. In normal healthy colon tissue from women, obesity and smoking increased DNA methylation at genes hypermethylated in cancer, but aspirin and hormone replacement therapy reduced DNA hypermethylation [153]. Therefore, a better understanding of differences in the prevalence of risk factors among CIMP subgroups across geographical regions could help unravel the pathways involved in CIMP CRC and explain disparities in CIMP prevalence across these regions. Racial, ethnic, and genetic differences in CIMP prevalence have also been previously reported. For instance, compared to patients of Southern European origin, the prevalence of CIMP tumors was higher in Australian-born CRC patients of Anglo-Celtic origin, suggesting a genetic predisposition to CIMP tumors among the latter population [154]. Other studies have also found evidence for a genetic basis for CIMP; for example, polymorphisms in genes such as MSH6 and MTHFR allele have been shown to be associated with CIMP-H tumors across diverse populations [151, 152, 155]. In addition, the authors also observed a joint effect of low folate, low methionine, high alcohol consumption, and MTHFR $1298 \mathrm{AC}$ or CC genotypes on the risk of CIMP+ CRC in the US study [156]. Hence possible differences in genetic makeup across countries can also underline differences in CIMP-H prevalence across geographical regions. Future studies should focus on a comprehensive assessment of lifestyle and genetic factors to compare differences and incidence of CIMP+ cancers across geographical regions.

Differences in utility of panels/methods for measuring CIMP significantly differed across continents, highlighting the rapid pace of development of the understanding of role of epigenetics in cancer and the associated technology and methodology used to quantify understanding of this phenotype. CIMP was first characterized by Issa et.al as a subset of highly methylated CRCs with features of concordant hypermethylation of multiple CpG island loci and bimodal distribution of the number of methylated CpG island loci using the 7-marker MINT panel [157]. The classical MINT marker panel paved the way for understanding methylation changes at the gene level. Lee et al. [158] later compared CIMP tumors using the classical and the Weisenberger panels. The Weissenberg panel was better at identifying the clinical, pathological, and molecular characteristics of CIMP tumors and worse at prognosis [158]. In 2007, Ogino et al. [12] proposed that a panel of 4 markers for CIMP-RUNX3, CACNA1G, IGF2, and MLH1-should be sensitive and specific enough for research and clinical use. Recently, the use of human methylation arrays have opened the door to an understanding of methylation across the whole genome [19]. Another difference among studies of CIMP is the utilization of primers and probes as well as identification of " $\mathrm{CpG}$ " probes and their location on the gene [9]. Differences in these methodological factors, in addition to differences in the background populations and thus the cohort compositions, might explain some of the variation in results obtained using different CIMP panels [76]. Other factors may include methods of tissue preservation, screening modalities, and patient selection criteria. This highlights the rapid pace of development of 
field of Epigenetics and transition from gene-specific panels to study of genome wide methylation across cancer patients.

The study of epigenetic modifications like CIMP is of growing interest to the fields of public health and cancer prevention, detection, and management. Assessing differences in the prevalence of CIMP across regions of the world is key to identifying factors that contribute to these changes and to developing primary cancer prevention strategies. CIMP can be present in precancerous "normal" tissue, raising cancer risk [159-162]. Because recent combined genetic and epigenetic analyses of sporadic CRC identified subsets possessing distinct clinicopathologic features, elucidation of the precise roles of epigenetic abnormalities such as CIMP might be a great help for the prevention, screening, and treatment of CRCs [163].

Our study has several strengths. First, we did not restrict our search strategy to any country or group of CRC patients. Second, to maintain uniformity we excluded CIMP studies focusing on precancerous lesions such as adenomas and polyps, as CIMP is considered to evolve from the serrated adenoma pathways [57, 164, 165]. Our study also had some limitations. First, because no gold standard exists for defining CIMP, comparisons of studies across panels or countries are challenging. Also, genetic markers across panels varied, including differences in cut-offs for defining CIMP groups within each methodological subtype too, which might add to possible heterogeneity in pooled prevalence of CIMP-H overall and across regions. Second, the high degree of heterogeneity in the results highlights the biological complexity of CIMP. Third, a few studies utilizing Weisenberger or Ogino panel had different cut-offs to determine CIMP within the same methodology which might lead to difference in prevalence of CIMP-H. Also the sensitivity of different methodologies or gene panels to quantify methylation might vary, possibly adding another source of heterogeneity in our results. Lastly, meta-regression has low power, and controlling for multiple factors in meta-regression analysis is not recommended. Hence, we decided to control only for methodology. By limiting to reports published in English, we may have excluded entire regions which report their findings in other languages. Though we identified positive correlation of CIMP-H prevalence with alcohol intake, these correlations do not imply causation and warrants further exploration in future studies. Finally, our results should be interpreted with caution due to small sample size in subgroup analysis and high heterogeneity identified in pooled analysis which might be due to factors other than methodology including differences in population characteristics, sampling variation, or by chance alone.
Through our study, we highlight the importance of considering variations in molecular methodologies in examining global variations of a disease phenotype. Further using principles of molecular pathology epidemiology, it is possible to examine the role of lifestyle, demographic and molecular factors in understanding possible mechanisms that explain possible differences in CIMP prevalence across geographical regions.

\section{Conclusion}

In summary, our results identified mean CIMP-H prevalence to be $22 \%$, with no differences observed between geographical regions. However, there were variations observed across countries within continents. In ecological analysis, CIMP-H prevalence showed strong correlation with alcohol intake at a global level, highlighting possible role of epigenetic mechanisms underlying this association. Finally, we also identified variations in methodologies used to quantify CIMP and need to identify a gold standard for making effective comparisons.

\section{Supplementary information}

Supplementary information accompanies this paper at https://doi.org/10. 1186/s12885-019-6144-9.

Additional file 1. Search Strategies for Systematic Review and Meta-analysis.

Additional file 2. Table summarizing CIMP methodologies.

Additional file 3. Funnel and Forest Plots for Meta-analysis.

Additional file 4. Bias Assessment for Cohort Studies.

Additional file 5. Bias Assessment for Case-Control Studies.

\section{Abbreviations}

CIMP: CpG island methylator phenotype; CRC: Colorectal cancer; MINT: Methylated in tumor; W-O: Weisenberger -Ogino

\section{Acknowledgements}

We would like to acknowledge the Department of Scientific Publications at the MD Anderson Cancer Center for their support in scientific editing the manuscript.

\section{Authors' contributions}

Design and Conceptualization: SA, SK. Manuscript Writing: SA, SK. Systematic Review search: HMV. Data Analysis: SA, PA, DWB, SMD. Manuscript Contribution and Revision of Manuscript: AMS, JSD, DSL, MDS, DB, CRD, KK, JB. All authors read and approved the final manuscript.

\section{Funding}

MDS is partially supported by a grant from the Cancer Prevention and Research Institute of Texas (CPRIT): RP170668.

Availability of data and materials

All materials have been cited in the manuscript.

Ethics approval and consent to participate

Not applicable

Consent for publication

Not applicable

Competing interests

The authors declare that they have no competing interests. 


\section{Author details}

'Department of Gastrointestinal Medical Oncology, The University of Texas MD Anderson Cancer Center, 1515 Holcombe Blvd, Unit 0426, Houston, TX 77030, USA. ${ }^{2}$ Cancer Prevention and Control Program, Lombardi Comprehensive Cancer Center, Georgetown University, Washington DC 20007, USA. ${ }^{3}$ Social Behavioral Research Branch, National Human Genome Research Institute, National Institute of Health, Bethesda, MD 20892, USA. ${ }^{4}$ Radiation Epidemiology Branch, Division of Cancer Epidemiology and Genetics, National Institutes of Health, National Cancer Institute, Rockville, MD 20850, USA. ${ }^{5}$ Department of Biostatistics and Data Science, School of Public Health, The University of Texas Health Science Center at Houston, Houston, TX 77030, USA. ' Library, School of Public Health, The University of Texas Health Science Center at Houston, Houston, TX 77030, USA.

${ }^{7}$ Department of Epidemiology, Human Genetics and Environmental Sciences, School of Public Health, The University of Texas Health Science Center at Houston, Houston, TX 77030, USA. ${ }^{8}$ Division of Urology- UTHealth McGovern Medical School, Houston, TX 77030, USA. ${ }^{9}$ Department of Preventive Medicine and Community Health, UTMB Health-School of Medicine, Galveston, TX 77555-1153, USA. ${ }^{10}$ Department of Epidemiology, The University of Texas MD Anderson Cancer Center, Houston, TX 77030, USA.

Received: 4 March 2019 Accepted: 10 September 2019 Published online: 17 October 2019

\section{References}

1. Bray F, Ferlay J, Soerjomataram I, Siegel RL, Torre LA, Jemal A. Global cancer statistics 2018: GLOBOCAN estimates of incidence and mortality worldwide for 36 cancers in 185 countries. CA Cancer J Clin. 2018;68:394.

2. Ferlay J, Soerjomataram I, Dikshit R, Eser S, Mathers C, Rebelo M, et al. Cancer incidence and mortality worldwide: sources, methods and major patterns in GLOBOCAN 2012. Int J Cancer. 2015;136(5):E359-E86.

3. Haggar FA, Boushey RP. Colorectal cancer epidemiology: incidence, mortality, survival, and risk factors. Clin Colon Rectal Surg. 2009;22(4):191.

4. Zong L, Abe M, Ji J, Zhu WG, Yu D. Tracking the correlation between CpG island methylator phenotype and other molecular features and clinicopathological features in human colorectal cancers: a systematic review and meta-analysis. Clin Transl Gastroenterol. 2016;7:e151.

5. Deschoolmeester $V$, Baay M, Specenier P, Lardon F, Vermorken JB. A review of the most promising biomarkers in colorectal cancer: one step closer to targeted therapy. Oncologist. 2010;15(7):699-731.

6. Toyota M, Ahuja N, Ohe-Toyota M, Herman JG, Baylin SB, Issa JP. CpG island methylator phenotype in colorectal cancer. Proc Natl Acad Sci U S A. 1999;96(15):8681-6.

7. Noffsinger AE. Serrated polyps and colorectal cancer: new pathway to malignancy. Annu Rev Pathol. 2009;4:343-64.

8. Juo YY, Johnston FM, Zhang DY, Juo HH, Wang H, Pappou EP, et al. Prognostic value of CpG island methylator phenotype among colorectal cancer patients: a systematic review and meta-analysis. Ann Oncol. 2014; 25(12):2314-27.

9. Hughes LA, Khalid-de Bakker CA, Smits KM, van den Brandt PA, Jonkers D, Ahuja N, et al. The CpG island methylator phenotype in colorectal cancer: progress and problems. Biochim Biophys Acta. 2012;1825(1):77-85.

10. Jia M, Gao X, Zhang Y, Hoffmeister M, Brenner H. Different definitions of CpG island methylator phenotype and outcomes of colorectal cancer: a systematic review. Clin Epigenetics. 2016;8:25.

11. Weisenberger DJ, Siegmund KD, Campan M, Young J, Long TI, Faasse MA, et al. CpG island methylator phenotype underlies sporadic microsatellite instability and is tightly associated with BRAF mutation in colorectal cancer. Nat Genet. 2006;38(7):787-93.

12. Ogino S, Kawasaki T, Kirkner GJ, Kraft P, Loda M, Fuchs CS. Evaluation of markers for CpG island methylator phenotype (CIMP) in colorectal cancer by a large population-based sample. J Mol Diagn. 2007;9(3):305-14.

13. Hinoue T, Weisenberger DJ, Lange CP, Shen H, Byun HM, Van Den Berg D, et al. Genome-scale analysis of aberrant DNA methylation in colorectal cancer. Genome Res. 2012;22(2):271-82.

14. Ahn JB, Chung WB, Maeda O, Shin SJ, Kim HS, Chung HC, et al. DNA methylation predicts recurrence from resected stage III proximal colon cancer. Cancer. 2011;117(9):1847-54.

15. Advani SM, Advani P, DeSantis SM, Brown D, VonVille HM, Lam M, et al. Clinical, pathological, and molecular characteristics of CpG island methylator phenotype in colorectal cancer: a systematic review and meta-analysis. Transl Oncol. 2018;11(5):1188.

16. VonVille H. Excel workbooks for systematic reviews; 2015.

17. Moher D, Liberati A, Tetzlaff J, Altman DG. Preferred reporting items for systematic reviews and meta-analyses: the PRISMA statement. BMJ. 2009; 339:b2535.

18. NCl. The cancer genome atlas: national institute of health. 2015. Available from: https://tcga-data.nci.nih.gov/tcga/.

19. $\mathrm{NCl}$. Comprehensive molecular characterization of human colon and rectal cancer. Nature. 2012;487(7407):330-7.

20. Borenstein M, Hedges LV, Higgins JP, Rothstein HR. A basic introduction to fixed-effect and random-effects models for meta-analysis. Res Synth Methods. 2010;1(2):97-111.

21. Thompson SG, Higgins J. How should meta-regression analyses be undertaken and interpreted? Stat Med. 2002;21(11):1559-73.

22. Wells G. The Newcastle-Ottawa Scale (NOS) for assessing the quality of nonrandomised studies in meta-analysis. 2004. http://www.ohri.ca/ programs/clinical_epidemiology/oxford.htm.

23. Sterne JA, Gavaghan D, Egger M. Publication and related bias in metaanalysis: power of statistical tests and prevalence in the literature. J Clin Epidemiol. 2000:53(11):1119-29.

24. Sterne JA, Egger M. Funnel plots for detecting bias in meta-analysis: guidelines on choice of axis. J Clin Epidemiol. 2001;54(10):1046-55.

25. Guinney J, Dienstmann R, Wang X, de Reynies A, Schlicker A, Soneson C, et al. The consensus molecular subtypes of colorectal cancer. Nat Med. 2015;21(11):1350-6.

26. Kim JH, Cho NY, Bae JM, Kim KJ, Rhee YY, Lee HS, et al. Nuclear maspin expression correlates with the $\mathrm{CpG}$ island methylator phenotype and tumor aggressiveness in colorectal cancer. Int J Clin Exp Pathol. 2015;8(2):1920-8.

27. Laskar RS, Ghosh SK, Talukdar FR. Rectal cancer profiling identifies distinct subtypes in India based on age at onset, genetic, epigenetic and clinicopathological characteristics. Mol Carcinog. 2015;54(12):1786-95.

28. Berg M, Nordgaard O, Korner H, Oltedal S, Smaaland R, Soreide JA, et al. Molecular subtypes in stage II-III colon cancer defined by genomic instability: early recurrence-risk associated with a high copy-number variation and loss of RUNX3 and CDKN2A. PLoS One. 2015;10(4):e0122391.

29. Weisenberger DJ, Levine AJ, Long TI, Buchanan DD, Walters R, Clendenning $\mathrm{M}$, et al. Association of the colorectal CpG island methylator phenotype with molecular features, risk factors, and family history. Cancer Epidemiol Biomark Prev. 2015;24(3):512-9.

30. Jorissen RN, Christie M, Mouradov D, Sakthianandeswaren A, Li S, Love C, et al. Wild-type APC predicts poor prognosis in microsatellite-stable proximal colon cancer. Br J Cancer. 2015;113(6):979-88.

31. Laskar RS, Talukdar FR, Choudhury JH, Singh SA, Kundu S, Dhar B, et al. Association of HPV with genetic and epigenetic alterations in colorectal adenocarcinoma from Indian population. Tumour Biol. 2015;36(6):4661-70.

32. Siraj AK, Prabhakaran S, Bavi P, Bu R, Beg S, Hazmi MA, et al. Prevalence of lynch syndrome in a middle eastern population with colorectal cancer. Cancer. 2015;121(11):1762-71.

33. Renaud F, Vincent A, Mariette C, Crepin M, Stechly L, Truant S, et al. MUC5AC hypomethylation is a predictor of microsatellite instability independently of clinical factors associated with colorectal cancer. Int J Cancer. 2015;136(12):2811-21.

34. Nosho K, Igarashi H, Ito M, Mitsuhashi K, Kurihara H, Kanno S, et al. Clinicopathological and molecular characteristics of serrated lesions in Japanese elderly patients. Digestion. 2015;91(1):57-63.

35. Kloten V, Rose M, Kaspar S, von Stillfried S, Knuchel R, Dahl E. Epigenetic inactivation of the novel candidate tumor suppressor gene ITIH5 in colon cancer predicts unfavorable overall survival in the CpG island methylator phenotype. Epigenetics. 2014;9(9):1290-301.

36. Shiovitz S, Bertagnolli MM, Renfro LA, Nam E, Foster NR, Dzieciatkowski S, et al. CpG island methylator phenotype is associated with response to adjuvant irinotecan-based therapy for stage III colon cancer. Gastroenterology. 2014;147(3):637-45.

37. Siraj AK, Bu R, Prabhakaran S, Bavi P, Beg S, Al Hazmi M, et al. A very low incidence of BRAF mutations in middle eastern colorectal carcinoma. Mol Cancer. 2014;13:168.

38. Luo Y, Wong CJ, Kaz AM, Dzieciatkowski S, Carter KT, Morris SM, et al. Differences in DNA methylation signatures reveal multiple pathways of progression from adenoma to colorectal cancer. Gastroenterology. 2014; 147(2):418-29 e8. 
39. Cleven AH, Derks S, Draht MX, Smits KM, Melotte V, Van Neste L, et al. CHFR promoter methylation indicates poor prognosis in stage II microsatellite stable colorectal cancer. Clin Cancer Res. 2014;20(12):3261-71.

40. Etienne-Grimaldi MC, Mahamat A, Chazal M, Laurent-Puig P, Olschwang S, Gaub MP, et al. Molecular patterns in deficient mismatch repair colorectal tumours: results from a French prospective multicentric biological and genetic study. Br J Cancer. 2014;110(11):2728-37.

41. Kohonen-Corish MR, Tseung J, Chan C, Currey N, Dent OF, Clarke S, et al, KRAS mutations and CDKN2A promoter methylation show an interactive adverse effect on survival and predict recurrence of rectal cancer. Int J Cancer. 2014;134(12):2820-8.

42. Deb S, Xu H, Tuynman J, George J, Yan Y, Li J, et al. RAD21 cohesin overexpression is a prognostic and predictive marker exacerbating poor prognosis in KRAS mutant colorectal carcinomas. Br J Cancer. 2014;110(6): 1606-13.

43. Dawson H, Galvan JA, Helbling M, Muller DE, Karamitopoulou E, Koelzer VH, et al. Possible role of $\mathrm{Cdx} 2$ in the serrated pathway of colorectal cancer characterized by BRAF mutation, high-level CpG Island methylator phenotype and mismatch repair-deficiency. Int J Cancer. 2014;134(10):2342-51.

44. Tahara T, Yamamoto E, Suzuki H, Maruyama R, Chung W, Garriga J, et al. Fusobacterium in colonic flora and molecular features of colorectal carcinoma. Cancer Res. 2014;74(5):1311-8.

45. Tahara T, Yamamoto E, Madireddi P, Suzuki H, Maruyama R, Chung W, et al. Colorectal carcinomas with CpG island methylator phenotype 1 frequently contain mutations in chromatin regulators. Gastroenterology. 2014;146(2): 530-38 e5.

46. Perea J, Rueda D, Canal A, Rodriguez Y, Alvaro E, Osorio I, et al. Age at onset should be a major criterion for subclassification of colorectal cancer. J Mol Diagn. 2014;16(1):116-26.

47. Pancione M, Remo A, Zanella C, Sabatino L, Di Blasi A, Laudanna C, et al. The chromatin remodelling component SMARCB1/INI1 influences the metastatic behavior of colorectal cancer through a gene signature mapping to chromosome 22. J Transl Med. 2013;11:297.

48. Walsh MD, Clendenning M, Williamson E, Pearson SA, Walters RJ, Nagler B, et al. Expression of MUC2, MUC5AC, MUC5B, and MUC6 mucins in colorectal cancers and their association with the $\mathrm{CpG}$ island methylator phenotype. Mod Pathol. 2013;26(12):1642-56.

49. Al-Temaimi RA, Jacob S, Al-Ali W, Thomas DA, Al-Mulla F. Reduced FHIT expression is associated with mismatch repair deficient and high CpG island methylator phenotype colorectal cancer. J Histochem Cytochem. 2013;61(9): 627-38.

50. Day FL, Jorissen RN, Lipton L, Mouradov D, Sakthianandeswaren A, Christie $M$, et al. PIK3CA and PTEN gene and exon mutation-specific clinicopathologic and molecular associations in colorectal cancer. Clin Cancer Res. 2013;19(12):3285-96.

51. Marisa L, de Reynies A, Duval A, Selves J, Gaub MP, Vescovo L, et al. Gene expression classification of colon cancer into molecular subtypes: characterization, validation, and prognostic value. PLoS Med. 2013;10(5):e1001453.

52. Donada M, Bonin S, Barbazza R, Pettirosso D, Stanta G. Management of stage II colon cancer - the use of molecular biomarkers for adjuvant therapy decision. BMC Gastroenterol. 2013;13:36

53. Oster B, Linnet L, Christensen LL, Thorsen K, Ongen H, Dermitzakis ET, et al. Non- $\mathrm{CpG}$ island promoter hypomethylation and miR-149 regulate the expression of SRPX2 in colorectal cancer. Int J Cancer. 2013;132(10):2303-15.

54. Yang Q, Dong Y, Wu W, Zhu C, Chong H, Lu J, et al. Detection and differential diagnosis of colon cancer by a cumulative analysis of promoter methylation. Nat Commun. 2012;3:1206.

55. Dallol A, Al-Maghrabi J, Buhmeida A, Gari MA, Chaudhary AG, Schulten HJ, et al. Methylation of the polycomb group target genes is a possible biomarker for favorable prognosis in colorectal cancer. Cancer Epidemiol Biomark Prev. 2012;21(11):2069-75.

56. Zlobec I, Bihl MP, Foerster A, Rufle A, Lugli A. The impact of CpG island methylator phenotype and microsatellite instability on tumour budding in colorectal cancer. Histopathology. 2012;61(5):777-87.

57. Yamamoto E, Suzuki H, Yamano HO, Maruyama R, Nojima M, Kamimae S, et al. Molecular dissection of premalignant colorectal lesions reveals early onset of the CpG island methylator phenotype. Am J Pathol. 2012;181(5): 1847-61.

58. Kakar S, Deng G, Smyrk TC, Cun L, Sahai V, Kim YS. Loss of heterozygosity, aberrant methylation, BRAF mutation and KRAS mutation in colorectal signet ring cell carcinoma. Mod Pathol. 2012;25(7):1040-7.
59. Isaksson-Mettavainio M, Palmqvist R, Dahlin AM, Van Guelpen B, Rutegard J, Oberg A, et al. High SMAD4 levels appear in microsatellite instability and hypermethylated colon cancers, and indicate a better prognosis. Int J Cancer. 2012;131(4):779-88.

60. Whitehall VL, Rickman C, Bond CE, Ramsnes I, Greco SA, Umapathy A, et al. Oncogenic PIK3CA mutations in colorectal cancers and polyps. Int J Cancer. 2012;131(4):813-20.

61. Jo P, Jung K, Grade M, Conradi LC, Wolff HA, Kitz J, et al. CpG island methylator phenotype infers a poor disease-free survival in locally advanced rectal cancer. Surgery. 2012;151(4):564-70.

62. Silver A, Sengupta N, Propper D, Wilson P, Hagemann T, Patel A, et al. A distinct DNA methylation profile associated with microsatellite and chromosomal stable sporadic colorectal cancers. Int J Cancer. 2012;130(5): 1082-92.

63. Konishi K, Watanabe Y, Shen L, Guo Y, Castoro RJ, Kondo K, et al. DNA methylation profiles of primary colorectal carcinoma and matched liver metastasis. PLoS One. 2011;6(11):e27889.

64. Zlobec I, Bihl M, Foerster A, Rufle A, Lugli A. Comprehensive analysis of CpG island methylator phenotype (CIMP)-high, -low, and -negative colorectal cancers based on protein marker expression and molecular features. J Pathol. 2011;225(3):336-43.

65. Min BH, Bae JM, Lee EJ, Yu HS, Kim YH, Chang DK, et al. The CpG island methylator phenotype may confer a survival benefit in patients with stage II or III colorectal carcinomas receiving fluoropyrimidine-based adjuvant chemotherapy. BMC Cancer. 2011;11:344.

66. Bruin SC, He Y, Mikolajewska-Hanclich I, Liefers GJ, Klijn C, Vincent A, et al. Molecular alterations associated with liver metastases development in colorectal cancer patients. Br J Cancer. 2011;105(2):281-7.

67. Karpinski P, Myszka A, Ramsey D, Kielan W, Sasiadek MM. Detection of viral DNA sequences in sporadic colorectal cancers in relation to CpG island methylation and methylator phenotype. Tumour Biol. 2011;32(4):653-9.

68. Jover R, Nguyen TP, Perez-Carbonell L, Zapater P, Paya A, Alenda C, et al. 5fluorouracil adjuvant chemotherapy does not increase survival in patients with $\mathrm{CpG}$ island methylator phenotype colorectal cancer. Gastroenterology. 2011;140(4):1174-81

69. Ibrahim AE, Arends MJ, Silva AL, Wyllie AH, Greger $L$, Ito $Y$, et al. Sequential DNA methylation changes are associated with DNMT3B overexpression in colorectal neoplastic progression. Gut. 2011;60(4):499-508.

70. Wong JJ, Hawkins NJ, Ward RL, Hitchins MP. Methylation of the 3p22 region encompassing MLH1 is representative of the $\mathrm{CPG}$ island methylator phenotype in colorectal cancer. Mod Pathol. 2011;24(3):396-411.

71. Limsui D, Vierkant RA, Tillmans LS, Wang AH, Weisenberger DJ, Laird PW, et al. Cigarette smoking and colorectal cancer risk by molecularly defined subtypes. J Natl Cancer Inst. 2010;102(14):1012-22.

72. Kim JC, Choi JS, Roh SA, Cho DH, Kim TW, Kim YS. Promoter methylation of specific genes is associated with the phenotype and progression of colorectal adenocarcinomas. Ann Surg Oncol. 2010;17(7):1767-76.

73. Ang PW, Loh M, Liem N, Lim PL, Grieu F, Vaithilingam A, et al. Comprehensive profiling of DNA methylation in colorectal cancer reveals subgroups with distinct clinicopathological and molecular features. BMC Cancer. 2010;10:227.

74. van Roon EH, van Puijenbroek M, Middeldorp A, van Eijk R, de Meijer EJ, Erasmus D, et al. Early onset MSI-H colon cancer with MLH1 promoter methylation, is there a genetic predisposition? BMC Cancer. 2010;10:180.

75. Arain MA, Sawhney M, Sheikh S, Anway R, Thyagarajan B, Bond JH, et al. CIMP status of interval colon cancers: another piece to the puzzle. Am J Gastroenterol. 2010;105(5):1189-95.

76. Dahlin AM, Palmqvist R, Henriksson ML, Jacobsson M, Eklof V, Rutegard J, et al. The role of the $\mathrm{CpG}$ island methylator phenotype in colorectal cancer prognosis depends on microsatellite instability screening status. Clin Cancer Res. 2010;16(6):1845-55.

77. Yagi K, Akagi K, Hayashi H, Nagae G, Tsuji S, Isagawa T, et al. Three DNA methylation epigenotypes in human colorectal cancer. Clin Cancer Res. 2010;16(1):21-33.

78. Hughes LA, van den Brandt PA, de Bruine AP, Wouters KA, Hulsmans S, Spiertz A, et al. Early life exposure to famine and colorectal cancer risk: a role for epigenetic mechanisms. PLoS One. 2009:4(11):e7951.

79. Sanchez JA, Krumroy L, Plummer S, Aung P, Merkulova A, Skacel M, et al. Genetic and epigenetic classifications define clinical phenotypes and determine patient outcomes in colorectal cancer. Br J Surg. 2009;96(10):1196-204. 
80. Seth R, Crook S, Ibrahem S, Fadhil W, Jackson D, Ilyas M. Concomitant mutations and splice variants in KRAS and BRAF demonstrate complex perturbation of the Ras/Raf signalling pathway in advanced colorectal cancer. Gut. 2009;58(9):1234-41.

81. Ostwald C, Linnebacher M, Weirich V, Prall F. Chromosomally and microsatellite stable colorectal carcinomas without the CpG island methylator phenotype in a molecular classification. Int J Oncol. 2009;35(2):321-7.

82. Ang PW, Li WQ, Soong R, lacopetta B. BRAF mutation is associated with the CpG island methylator phenotype in colorectal cancer from young patients. Cancer Lett. 2009;273(2):221-4.

83. Barault L, Charon-Barra C, Jooste V, de la Vega MF, Martin L, Roignot P, et al. Hypermethylator phenotype in sporadic colon cancer: study on a population-based series of 582 cases. Cancer Res. 2008;68(20):8541-6.

84. Fukuyama R, Niculaita R, Ng KP, Obusez E, Sanchez J, Kalady M, et al. Mutated in colorectal cancer, a putative tumor suppressor for serrated colorectal cancer, selectively represses beta-catenin-dependent transcription. Oncogene. 2008;27(46):6044-55.

85. Cai G, Xu Y, Lu H, Shi Y, Lian P, Peng J, et al. Clinicopathologic and molecular features of sporadic microsatellite- and chromosomal-stable colorectal cancers. Int J Color Dis. 2008;23(4):365-73.

86. Deng G, Kakar S, Tanaka H, Matsuzaki K, Miura S, Sleisenger MH, et al. Proximal and distal colorectal cancers show distinct gene-specific methylation profiles and clinical and molecular characteristics. Eur J Cancer. 2008;44(9):1290-301.

87. Kakar S, Deng G, Sahai V, Matsuzaki K, Tanaka H, Miura S, et al. Clinicopathologic characteristics, CpG island methylator phenotype, and BRAF mutations in microsatellite-stable colorectal cancers without chromosomal instability. Arch Pathol Lab Med. 2008;132(6):958-64.

88. Suehiro Y, Wong CW, Chirieac LR, Kondo Y, Shen L, Webb CR, et al. Epigenetic-genetic interactions in the APCNNT, RAS/RAF, and P53 pathways in colorectal carcinoma. Clin Cancer Res. 2008;14(9):2560-9.

89. Ferracin M, Gafa R, Miotto E, Veronese A, Pultrone C, Sabbioni S, et al. The methylator phenotype in microsatellite stable colorectal cancers is characterized by a distinct gene expression profile. J Pathol. 2008;214(5): 594-602.

90. lacopetta B, Grieu F, Phillips M, Ruszkiewicz A, Moore J, Minamoto T, et al. Methylation levels of LINE-1 repeats and CPG island loci are inversely related in normal colonic mucosa. Cancer Sci. 2007;98(9):1454-60.

91. Goel A, Nagasaka T, Arnold CN, Inoue T, Hamilton C, Niedzwiecki D, et al. The CpG island methylator phenotype and chromosomal instability are inversely correlated in sporadic colorectal cancer. Gastroenterology. 2007;132(1):127-38.

92. Sugai T, Habano W, Jiao YF, Tsukahara M, Takeda Y, Otsuka K, et al. Analysis of molecular alterations in left- and right-sided colorectal carcinomas reveals distinct pathways of carcinogenesis: proposal for new molecular profile of colorectal carcinomas. J Mol Diagn. 2006;8(2):193-201.

93. Tanaka H, Deng G, Matsuzaki K, Kakar S, Kim GE, Miura S, et al. BRAF mutation, CpG island methylator phenotype and microsatellite instability occur more frequently and concordantly in mucinous than non-mucinous colorectal cancer. Int J Cancer. 2006;118(11):2765-71.

94. Anacleto C, Leopoldino AM, Rossi B, Soares FA, Lopes A, Rocha JC, et al. Colorectal cancer "methylator phenotype": fact or artifact? Neoplasia. 2005;7(4):331-5.

95. Oyama K, Kawakami K, Maeda K, Ishiguro K, Watanabe G. The association between methylenetetrahydrofolate reductase polymorphism and promoter methylation in proximal colon cancer. Anticancer Res. 2004;24(2B):649-54.

96. Yamashita K, Dai T, Dai Y, Yamamoto F, Perucho M. Genetics supersedes epigenetics in colon cancer phenotype. Cancer Cell. 2003;4(2):121-31.

97. Frazier ML, Xi L, Zong J, Viscofsky N, Rashid A, Wu EF, et al. Association of the CpG island methylator phenotype with family history of cancer in patients with colorectal cancer. Cancer Res. 2003;63(16):4805-8.

98. van Rijnsoever M, Grieu F, Elsaleh H, Joseph D, lacopetta B. Characterisation of colorectal cancers showing hypermethylation at multiple CpG islands. Gut. 2002;51(6):797-802.

99. Toyota M, Ohe-Toyota M, Ahuja N, Issa JP. Distinct genetic profiles in colorectal tumors with or without the CpG island methylator phenotype. Proc Natl Acad Sci U S A. 2000;97(2):710-5.

100. Chen KH, Lin YL, Liau JY, Tsai JH, Tseng LH, Lin LI, et al. BRAF mutation may have different prognostic implications in early- and late-stage colorectal cancer. Med Oncol. 2016;33(5):39.

101. Carr PR, Jansen L, Walter V, Kloor M, Roth W, Blaker H, et al. Associations of red and processed meat with survival after colorectal cancer and differences according to timing of dietary assessment. Am J Clin Nutr. 2016;103(1):192-200.

102. Bae JM, Kim JH, Rhee YY, Cho NY, Kim TY, Kang GH. Annexin A10 expression in colorectal cancers with emphasis on the serrated neoplasia pathway. World J Gastroenterol. 2015;21(33):9749-57.

103. Ichimura N, Shinjo K, An B, Shimizu Y, Yamao K, Ohka F, et al. Aberrant TET1 methylation closely associated with CpG island methylator phenotype in colorectal cancer. Cancer Prev Res (Phila). 2015;8(8):702-11.

104. Li X, Hu F, Wang Y, Yao X, Zhang Z, Wang F, et al. CpG island methylator phenotype and prognosis of colorectal cancer in Northeast China. Biomed Res Int. 2014;2014:236361.

105. Perea J, Cano JM, Rueda D, Garcia JL, Inglada L, Osorio I, et al. Classifying early-onset colorectal cancer according to tumor location: new potential subcategories to explore. Am J Cancer Res. 2015;5(7):2308-13.

106. Wang Y, Long Y, Xu Y, Guan Z, Lian P, Peng J, et al. Prognostic and predictive value of $\mathrm{CpG}$ island methylator phenotype in patients with locally advanced nonmetastatic sporadic colorectal cancer. Gastroenterol Res Pract. 2014;2014:436985.

107. Poole EM, Curtin K, Hsu L, Kulmacz RJ, Duggan DJ, Makar KW, et al. Genetic variability in EGFR, Src and HER2 and risk of colorectal adenoma and cancer. Int J Mol Epidemiol Genet. 2011;2(4):300-15.

108. Cohen SA, Wu C, Yu M, Gourgioti G, Wirtz R, Raptou G, et al. Evaluation of CPG island methylator phenotype as a biomarker in colorectal cancer treated with adjuvant Oxaliplatin. Clin Colorectal Cancer. 2016;15(2):164-9.

109. Maeda T, Suzuki K, Togashi K, Nokubi M, Saito M, Tsujinaka S, et al. Sessile serrated adenoma shares similar genetic and epigenetic features with microsatellite unstable colon cancer in a location-dependent manner. Exp Ther Med. 2011;2(4):695-700.

110. Jia M, Jansen $L$, Walter $V$, Tagscherer $K$, Roth $W$, Herpel $E$, et al. No association of $\mathrm{CpG}$ island methylator phenotype and colorectal cancer survival: population-based study. Br J Cancer. 2016;115(11):1359-66.

111. Ling A, Lundberg IV, Eklof V, Wikberg ML, Oberg A, Edin S, et al. The infiltration, and prognostic importance, of Th1 lymphocytes vary in molecular subgroups of colorectal cancer. J Pathol Clin Res. 2016;2(1):21-31.

112. Zhang X, Shimodaira H, Soeda H, Komine K, Takahashi H, Ouchi K, et al. CpG island methylator phenotype is associated with the efficacy of sequential oxaliplatin- and irinotecan-based chemotherapy and EGFR-related gene mutation in Japanese patients with metastatic colorectal cancer. Int J Clin Oncol. 2016;21(6):1091-101.

113. Mima K, Nowak JA, Qian ZR, Cao Y, Song M, Masugi Y, et al. Tumor LINE-1 methylation level and colorectal cancer location in relation to patient survival. Oncotarget. 2016;7(34):55098-109.

114. Minarikova P, Benesova L, Halkova T, Belsanova B, Suchanek S, Cyrany J, et al. Longitudinal molecular characterization of endoscopic specimens from colorectal lesions. World J Gastroenterol. 2016;22(20): 4936-45.

115. Suraweera N, Mouradov D, Li S, Jorissen RN, Hampson D, Ghosh A, et al. Relative telomere lengths in tumor and normal mucosa are related to disease progression and chromosome instability profiles in colorectal cancer. Oncotarget. 2016;7(24):36474-88.

116. Sawada T, Yamamoto E, Yamano HO, Nojima M, Harada T, Maruyama R, et al. Assessment of epigenetic alterations in early colorectal lesions containing BRAF mutations. Oncotarget. 2016;7(23):35106-18.

117. Hokazono K, Ueki T, Nagayoshi K, Nishioka Y, Hatae T, Koga Y, et al. A CpG island methylator phenotype of colorectal cancer that is contiguous with conventional adenomas, but not serrated polyps. Oncol Lett. 2014;8(5): 1937-44.

118. Rasuck CG, Leite SM, Komatsuzaki F, Ferreira AC, Oliveira VC, Gomes KB. Association between methylation in mismatch repair genes, V600E BRAF mutation and microsatellite instability in colorectal cancer patients. Mol Biol Rep. 2012;39(3):2553-60.

119. Van Guelpen B, Dahlin AM, Hultdin J, Eklof V, Johansson I, Henriksson ML, et al. One-carbon metabolism and CpG island methylator phenotype status in incident colorectal cancer: a nested case-referent study. Cancer Causes Control. 2010;21(4):557-66

120. Meng H, Li W, Boardman LA, Wang L. Loss of ZG16 is associated with molecular and clinicopathological phenotypes of colorectal cancer. BMC Cancer. 2018;18(1):433.

121. Boulagnon-Rombi C, Schneider C, Leandri C, Jeanne A, Grybek V, Bressenot AM, et al. LRP1 expression in colon cancer predicts clinical outcome. Oncotarget. 2018;9(10):8849. 
122. Fennell $L$, Jamieson $S$, McKeone $D$, Corish $T$, Rohdmann M, Furner $T$, et al. MLH1-93 G/a polymorphism is associated with MLH1 promoter methylation and protein loss in dysplastic sessile serrated adenomas with BRAF V600E mutation. BMC Cancer. 2018;18(1):35.

123. Kokelaar RF, Jones HG, Williamson J, Williams N, Griffiths AP, Beynon J, et al. DNA hypermethylation as a predictor of extramural vascular invasion (EMVI) in rectal cancer. Cancer Biol Ther. 2018;19(3):214-21.

124. Saadallah-Kallel A, Abdelmaksoud-Dammak R, Triki M, Charfi S, Khabir A, Sallemi-Boudawara T, et al. Clinical and prognosis value of the CIMP status combined with MLH1 or p16INK4a methylation in colorectal cancer. Med Oncol. 2017;34(8):147.

125. Alvi MA, Loughrey MB, Dunne P, McQuaid S, Turkington R, Fuchs M-A, et al. Molecular profiling of signet ring cell colorectal cancer provides a strong rationale for genomic targeted and immune checkpoint inhibitor therapies. Br J Cancer. 2017;117(2):203.

126. Williamson JS, Jones HG, Williams N, Griffiths AP, Jenkins G, Beynon J, et al. Extramural vascular invasion and response to neoadjuvant chemoradiotherapy in rectal cancer: influence of the CpG island methylator phenotype. World J Gastrointest Oncol. 2017;9(5):209.

127. Vedeld HM, Merok M, Jeanmougin M, Danielsen SA, Honne H, Presthus GK, et al. CpG island methylator phenotype identifies high risk patients among microsatellite stable BRAF mutated colorectal cancers. Int J Cancer. 2017 141(5):967-76.

128. Sambuudash O, Kim H-S, Cho MY. Lack of aberrant methylation in an adjacent area of left-sided colorectal cancer. Yonsei Med J. 2017;58(4):749-55.

129. Cohen SA, Yu M, Baker K, Redman M, Wu C, Heinzerling TJ, et al. The CpG island methylator phenotype is concordant between primary colorectal carcinoma and matched distant metastases. Clin Epigenetics. 2017:9(1):46.

130. Lee C-T, Huang Y-C, Hung L-Y, Chow N-H, Su P-F, Ho C-L, et al. Serrated adenocarcinoma morphology in colorectal mucinous adenocarcinoma is associated with improved patient survival. Oncotarget. 2017:8(21):35165.

131. Mclnnes T, Zou D, Rao DS, Munro FM, Phillips VL, McCall JL, et al. Genomewide methylation analysis identifies a core set of hypermethylated genes in CIMP-H colorectal cancer. BMC Cancer. 2017;17(1):228.

132. Jones $H G$, Jenkins $G$, Williams N, Griffiths P, Chambers P, Beynon J, et al. Genetic and epigenetic intra-tumour heterogeneity in colorectal cancer. World J Surg. 2017:41(5):1375-83.

133. Kim CH, Huh JW, Kim HR, Kim YJ. CpG island methylator phenotype is an independent predictor of survival after curative resection for colorectal cancer: a prospective cohort study. J Gastroenterol Hepatol. 2017;32(8): 1469-74.

134. WHO. World Health Organization: health topics. 2018. Available from: https://www.who.int/.

135. Tsoi KK, Pau CY, Wu WK, Chan FK, Griffiths S, Sung JJ. Cigarette smoking and the risk of colorectal cancer: a meta-analysis of prospective cohort studies. Clin Gastroenterol Hepatol. 2009;7(6):682-8. e5.

136. Bongaerts BW, van den Brandt PA, Goldbohm RA, de Goeij AF, Weijenberg MP. Alcohol consumption, type of alcoholic beverage and risk of colorectal cancer at specific subsites. Int J Cancer. 2008;123(10):2411-7.

137. Ma Y, Yang Y, Wang F, Zhang P, Shi C, Zou Y, et al. Obesity and risk of colorectal cancer: a systematic review of prospective studies. PLoS One. 2013;8(1):e53916.

138. Kamangar F, Dores GM, Anderson WF. Patterns of cancer incidence, mortality, and prevalence across five continents: defining priorities to reduce cancer disparities in different geographic regions of the world. J Clin Oncol Off J Am Soc Clin Oncol. 2006;24(14):2137-50.

139. Young JP, Win AK, Rosty C, Flight I, Roder D, Young GP, et al. Rising incidence of early-onset colorectal cancer in Australia over two decades: report and review. J Gastroenterol Hepatol. 2015;30(1):6-13.

140. Sung JJ, Lau JY, Goh KL, Leung WK. Increasing incidence of colorectal cancer in Asia: implications for screening. Lancet Oncol. 2005;6(11):871-6.

141. Jemal A, Bray F, Center MM, Ferlay J, Ward E, Forman D. Global cancer statistics. CA Cancer J Clin. 2011;61(2):69-90.

142. Center MM, Jemal A, Ward E. International trends in colorectal cancer incidence rates. Cancer Epidemiol Biomark Prev. 2009;18(6):1688-94.

143. Huxley RR, Ansary-Moghaddam A, Clifton P, Czernichow S, Parr CL, Woodward M. The impact of dietary and lifestyle risk factors on risk of colorectal cancer: a quantitative overview of the epidemiological evidence. Int J Cancer. 2009;125(1):171-80.

144. Hughes LA, Simons CC, van den Brandt PA, Goldbohm RA, de Goeij AF, de Bruine AP, et al. Body size, physical activity and risk of colorectal cancer with or without the CpG island methylator phenotype (CIMP). PLoS One. 2011;6(4):e18571.

145. Slattery ML, Curtin K, Sweeney C, Levin TR, Potter J, Wolff RK, et al. Diet and lifestyle factor associations with CPG island methylator phenotype and BRAF mutations in colon cancer. Int J Cancer. 2007;120(3):656-63.

146. Slattery ML, Wolff RK, Herrick JS, Curtin K, Caan BJ, Samowitz W. Alcohol consumption and rectal tumor mutations and epigenetic changes. Dis Colon Rectum. 2010;53(8):1182-9.

147. Ogino S, Nosho K, Irahara N, Meyerhardt JA, Baba Y, Shima K, et al. Lymphocytic reaction to colorectal cancer is associated with longer survival, independent of lymph node count, microsatellite instability, and CpG island methylator phenotype. Clin Cancer Res. 2009;15(20):6412-20.

148. Samowitz WS, Albertsen H, Sweeney C, Herrick J, Caan BJ, Anderson KE, et al. Association of smoking, CpG island methylator phenotype, and V600E BRAF mutations in colon cancer. J Natl Cancer Inst. 2006:98(23):1731-8.

149. Nishihara R, Morikawa T, Kuchiba A, Lochhead P, Yamauchi M, Liao X, et al. A prospective study of duration of smoking cessation and colorectal cancer risk by epigenetics-related tumor classification. Am J Epidemiol. 2013;178(1): 84-100.

150. Slattery ML, Curtin K, Wolff RK, Herrick JS, Caan BJ, Samowitz W. Diet, physical activity, and body size associations with rectal tumor mutations and epigenetic changes. Cancer Causes Control. 2010;21(8):1237-45.

151. Liu L, Nishihara R, Qian ZR, Tabung FK, Nevo D, Zhang X, et al. Association between inflammatory diet pattern and risk of colorectal carcinoma subtypes classified by immune responses to tumor. Gastroenterology. 2017; 153(6):1517-30. e14

152. Daniel CR, Cross AJ, Koebnick C, Sinha R. Trends in meat consumption in the USA. Public Health Nutr. 2011;14(4):575-83.

153. Noreen F, Roosli M, Gaj P, Pietrzak J, Weis S, Urfer P, et al. Modulation of age- and cancer-associated DNA methylation change in the healthy colon by aspirin and lifestyle. J Natl Cancer Inst. 2014;106(7):1-9.

154. English DR, Young JP, Simpson JA, Jenkins MA, Southey MC, Walsh MD, et al. Ethnicity and risk for colorectal cancers showing somatic BRAF V600E mutation or CpG island methylator phenotype. Cancer Epidemiol Biomark Prev. 2008;17(7):1774-80.

155. Curtin K, Samowitz WS, Wolff RK, Caan BJ, Ulrich CM, Potter JD, et al. MSH6 G39E polymorphism and CpG island methylator phenotype in colon cancer. Mol Carcinog. 2009;48(11):989-94.

156. Curtin K, Slattery ML, Ulrich CM, Bigler J, Levin TR, Wolff RK, et al. Genetic polymorphisms in one-carbon metabolism: associations with $\mathrm{CpG}$ island methylator phenotype (CIMP) in colon cancer and the modifying effects of diet. Carcinogenesis. 2007;28(8):1672-9.

157. Issa JP. CpG island methylator phenotype in cancer. Nat Rev Cancer. 2004:4(12):988-93.

158. Lee S, Cho NY, Yoo EJ, Kim JH, Kang GH. CpG island methylator phenotype in colorectal cancers: comparison of the new and classic CpG island methylator phenotype marker panels. Arch Pathol Lab Med. 2008;132(10): 1657-65.

159. Kaneda A, Feinberg AP. Loss of imprinting of IGF2: a common epigenetic modifier of intestinal tumor risk. Cancer Res. 2005:65(24):11236-40.

160. Kaneda A, Yagi K. Two groups of DNA methylation markers to classify colorectal cancer into three epigenotypes. Cancer Sci. 2011;102(1):18-24.

161. Baylin SB, Ohm JE. Epigenetic gene silencing in cancer - a mechanism for early oncogenic pathway addiction? Nat Rev Cancer. 2006;6(2):107-16.

162. Feinberg AP, Ohlsson $R$, Henikoff $S$. The epigenetic progenitor origin of human cancer. Nat Rev Genet. 2006;7(1):21-33.

163. Kondo Y, Issa JP. Epigenetic changes in colorectal cancer. Cancer Metastasis Rev. 2004;23(1-2):29-39.

164. Spring KJ, Zhao ZZ, Karamatic R, Walsh MD, Whitehall VL, Pike T, et al. High prevalence of sessile serrated adenomas with BRAF mutations: a prospective study of patients undergoing colonoscopy. Gastroenterology. 2006;131(5): 1400-7.

165. Leggett $B$, Whitehall $V$. Role of the serrated pathway in colorectal cancer pathogenesis. Gastroenterology. 2010;138(6):2088-100.

\section{Publisher's Note}

Springer Nature remains neutral with regard to jurisdictional claims in published maps and institutional affiliations. 